\title{
Experimental and Numerical Analysis of High-Speed Internally Cooled Milling
}

\author{
Ningxia Yin*, Liangliang Lv, JingyueWu,Guanghui Li, Guangyu Tan \\ School of Mechanical and Power Engineering, Guangdong Ocean University, Zhanjiang, Guangdong, \\ China \\ *Corresponding Author.
}

\begin{abstract}
Advanced cooling technology is a crucial measure of thermal dissipation for high-speed end-milling. In order to get an appropriate cooling technology and decrease the negative effects of traditional wet cutting, internally cooled cutting has been paid more and more attention. Because of interrupted cutting and uneven force, there was few application and investigation on internally cooled end-milling. In the paper, the effect of the end-milling tool with different internally cooled channel structure has been researched by experiment and theoretical analysis. The experimental results indicate that the end-milling tool with double helix channels carried out best machined surface quality. And the experiment result was also been analyzed and explained by computational fluid dynamics simulation, which provides a basis for the applying of the high-speed internally cooled end-milling tool.
\end{abstract}

Keywords: High-speed internally cooled milling, cutting fluid, Computational fluid dynamics (CFD), Surface quality

\section{Introduction}

In conventional machining, cutting fluid can reduce the tool wear, extending the cutter service life, improve surface quality, and remove chip, but many fluidsare harmful to human and environment. In addition, some of the waste cutting fluid is difficult to recycle, so the use of the external cooling has been minimized and gradually become obsolete. A perfect alternative to traditional cooling and lubricating method is dry cutting, without any cutting fluid [1], so the defect of using cutting fluid can be avoided. And there are some scientific research performed on dry machining [2-3]. At the same time, it is very important to reduce the cost of use of cutting fluid. Although dry cutting is drawn attention and it also becomes the pursuit of the ultimate goal of green cutting, the use of dry machining leads to a significant reduction of tool life, dry cutting cannot be used in many occasions, especially not suitable the manufacturing of difficult-to-process materials. This is because that there will be a lot friction wear and adhesion wearbetween tool-chip contact area and tool-workpiece contact area. At the same time, with the more and more extensive application of difficult-to-cut materials like stainless steels, titanium and Ni base alloys which are widely used in aerospace components, engine parts, stationary power plants and medical applications [4], one problem is more and more outstanding, which is the high temperature at the center cutting area. The increase temperature in high speed cutting reduces machining accuracy and shortens tool service life, and even make the cutting process cannot be completed [5]. Too much cutting heat too late to dissipate and its induced wear are the two main important factors that affect the lifetime of the end mill, surface quality and machining precision of the workpiece. While in machining, there are also some flammable and explosive materials, so as to improve the cutter life and abrasion resistance, internally cooled cutting is creasing used which can drastically enhance lubrication and cooling.

Cutting fluid can perform not only as coolant but also as lubricant during internally cooled cutting. As coolant, the fluid can effectively drop the cutting zone temperature, and as the lubricant, the fluid can decrease friction factor between the tool and the workpiece. So the cutting force becomes lower than dry cutting. Internally cooled drilling,

ISSN: 0010-8189

(C) CONVERTER 2021

www.converter-magazine.info 
strength evenly, and internally cooled screw tap, cutting time shortly, cutting speed lowly, have been applied more and more. So the internally cooled cutting is an effective alternative in reducing cutting temperature and extending tool life. Nevertheless, in the past decade, the internally cooled technology haven't been utilized in many manufacturing centers, possibly because of incompatibilities of internally cooled system with the existing machinery, cost burden associated with modification internally cooled system. Fortunately, the research about internally cooled milling has attracted more and more attention recently [6]. Zhang[6] analyzed the main impact of three internal structure tools on cutting forces and cutter life under CMQL cutting condition through experiment, and furthermore it was found that the effect of the double straight channel was better than double helical channel and single straight channel. Zhao et al. [7] found the positive effect of the internally cooled on the milling cutter wear during orthogonal cutting, and they found that the carbide tool life with internally cooled could be increased up to $15 \%$ than the ordinary tool. And many industrial engineers have come to realize the potential productivity gains offered by internally cooled technology, the internally cooled technology is increasingly used in some new machining centers. At the same time, high-pressure coolant could reduce the manufacturing cycle time and component cost in non-high-speed milling and drilling.

Although in fact, the high-speed end-milling tool with internally cooled holes is advantageous to feed the cutting fluid to the cutting zone [5], thus the cutting zone temperature can be reduced by $246^{\circ} \mathrm{C}$ from dry cutting to wet cuttingand the end-milling tool life is also improved. Up until recently, the investigationabout the cutting zone mixed flow in high speed internal cool end milling is rarely [6]. It is chiefly because that the end milling is a very complex interrupted cutting process, some significant physical phenomena are hard to comprehend. So it is necessary to give a suitable structure and position of the internally cooled channels which can promote its study with greater strength for speedy perfection.

Computational fluid dynamics (CFD) is aneffective simulation tool which is becoming widely used to compute many industrial problems and the simulate results as research tools are proved for extensive use [8]. And it has been used for estimate and illustration the flow behavior of machinery such as cooling fluid flow duringthe process drilling, turning and grinding $[9,10]$. The simulation method also applies to high-speed internally cooled endmilling. Thus, in this study, the mixed flow field of the cutting areaduring high speed internally cooled milling hole is created and the influence of the internally cooled channel structure on the end mill cutter is discussed through the support of CFD simulations. At the same time, the experiment of internally cooled end-milling steel 55 is carried out, the surface quality of machined workpiece from the experiments agrees to a certain extent with the numerical simulation and it indicates that this validation method is effective.

\section{Computational Models}

The model was builtaccording to the used solid carbide end mill geometry in the experiment. The adapted steps to run the calculation are as follows: 1) Establishment 3D geometry model, 2) discretization 3D geometry model;3) setting boundary conditions.

\subsection{D geometry model}

To improve the cutting fluid cooling effect, two kinds of end-mill cutters with two different cooling channel geometries of double helical channels (DHC) and double straight channels (DSC) have been designed in the paper. The 3D geometry model of the investigated end mill is shown in Fig 1. Except the different internally cooled channels structure, both of the selected end-mill cutters have the same exterior structure parameter. The diameter is $12 \mathrm{~mm}$, the total length of the cutters is both $80 \mathrm{~mm}$, and the helix angel is $35^{\circ}$. The internally cooled channel diameters are both $1.4 \mathrm{~mm}$, and the holesdistance is $6.25 \mathrm{~mm}$. To focus on the flow of the internally cooled fluid closing cutting edges, the active length of $l \mathrm{a}=20 \mathrm{~mm}$ is chosen to be modeled.

ISSN: 0010-8189

(C) CONVERTER 2021

www.converter-magazine.info 


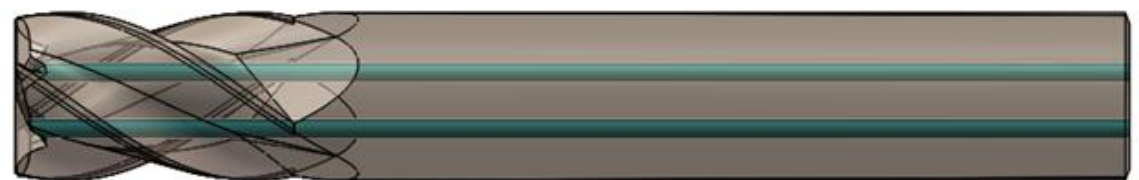

(a) End mill cutters of DSC

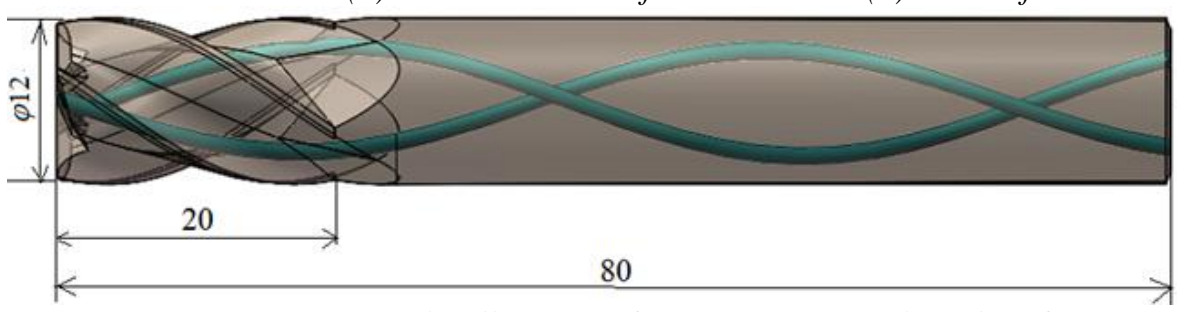

(c) End mill cutters of DHC Fig 1: End mill cutters and internally cooled channel
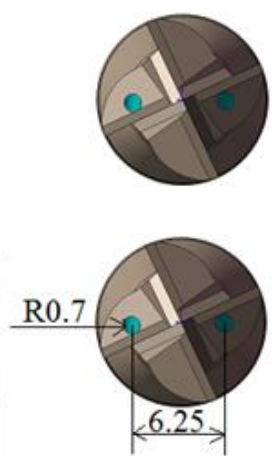

\subsection{Meshing of the model}

Turbulence model and fine meshing play an important role in the simulation of internally cooled end-milling process. Because of the complicated geometry of the end-milling tool and geometric features in very small dimension closeevery cutting edge, it is difficult to mesh. Furthermore it is easy to appear the phenomenon of large mesh distortion rate or negative volume, which causes poor quality elements or even computation interruption. According to the above reasons, the tetrahedral mesh is used in the simulation, and mesh around the bottom cutting zone and the internally cooled channel is local refined. The cutting area mesh structure is shown as Fig 2.

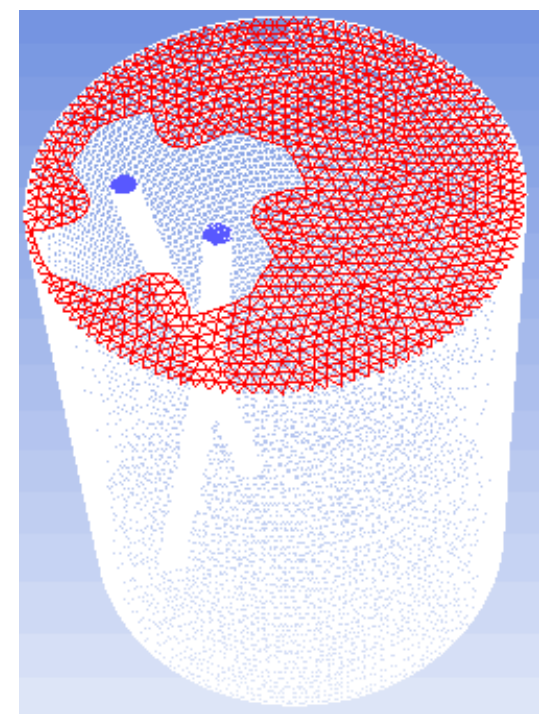

Fig2: Mesh Structure of cutting area

\subsection{Fluid model and boundary condition}

Simplified orthogonal metal cutting is employed to investigate the properties of high speed end mill flow field under internally cooled. The simplified end mill models of a workpiece under end milling a $16 \mathrm{~mm}$ hole, an end mill cutter with two internally cooled channels are put together in the domain schematically shown in Fig 3. During the end mill modeling, the main assumptions are as follows: (1) The fluid flows steady in the end mill cutter entrance, and there is no instantaneous surge and shock of the cutting fluid; (2) The reflux of air into the end mill via the outlet of internally cooled channel is ignored; (3) The end milled hole-bottom is smooth.

The computational model of the end mill with two internally cooled channels was imported into the commercial

ISSN: 0010-8189

www.converter-magazine.info 
software ANSYS/Fluent simulation environment.
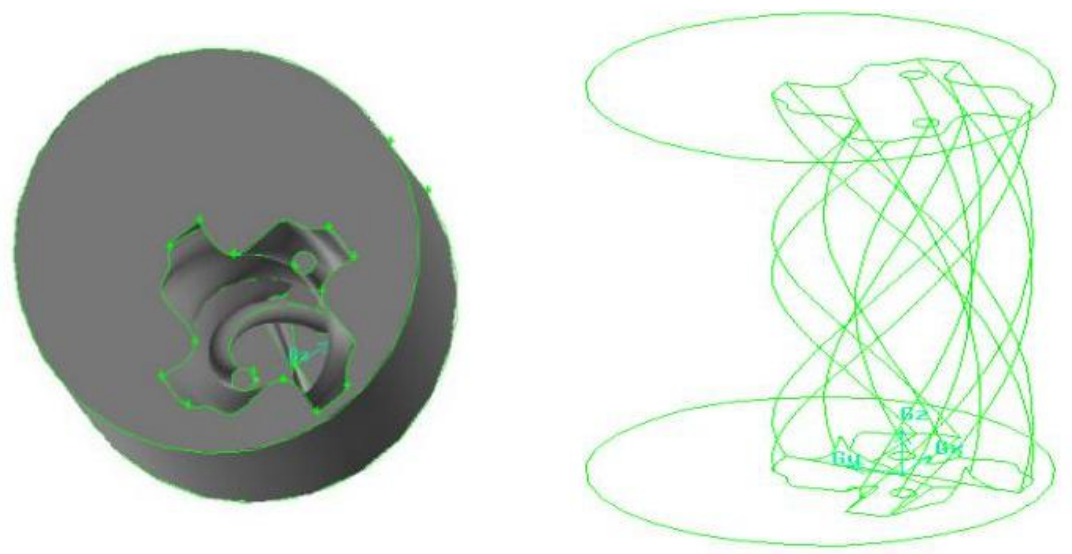

Fig 3: Simplified flow field domain

In order to realize that the cutting fluid between end mill cutter and fluid are approach to the true flow, the initial and boundary conditionin the simulationare setup as follows: theinlet pipe gauge pressureof the internally cooled channel was set as $0.3 \mathrm{MPa}$, and its direct was vertical to the boundary, the outlet boundary is the Neumann boundary, so its reference pressure can be set to an ambient pressure. The inlet and outlet are shown as Fig 4 . The whole setup of the cutting fluid centrifugal acceleration is according to the $10000 \mathrm{rpm}$. On account of the shear stress transport (SST) is capable inobtaininghigh accuracy on both near wall or far-from wall, the SST turbulence model was adopted. The cutting fluid is regarded asincompressible.
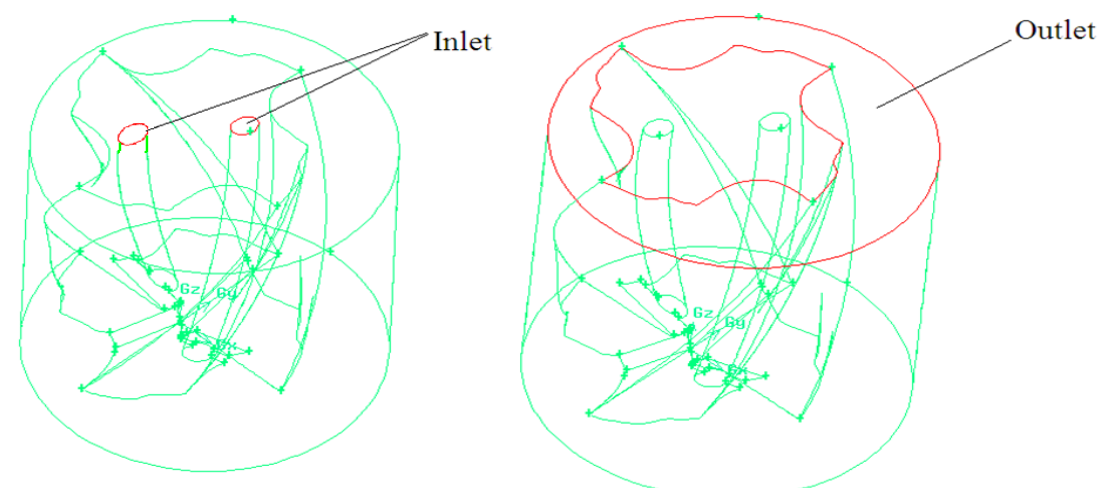

Fig 4: Inlet and Outlet

\section{Experimental Details}

\subsection{Workpiece material and cutting tools}

In the area of machining shaft parts, steel 55 has been commonly used due to its better mechanical properties. So in the paper, steel 55 is chosen for the workpiece material. It has been used in the paper is a rectangular block with a dimension of $160 \mathrm{~mm} \times 82 \mathrm{~mm} \times 50 \mathrm{~mm}$. Table 1 and Table 2 show chemical composition, typical mechanical behavior of the workpiece, respectively. Forpurpose of removing the workpiece surface oxidation layer's effects, the outer surface layer of the steel 55 is removed before the experiment. 
Table 1 Chemical composition of 55steel

\begin{tabular}{|c|c|c|c|c|c|c|c|c|c|}
\hline Element & & $\mathrm{C}$ & $\mathrm{Mn}$ & $\mathrm{Si}$ & $\mathrm{S}$ & $\mathrm{P}$ & $\mathrm{Cr}$ & $\mathrm{Ni}$ & $\mathrm{Cu}$ \\
\hline \multirow{2}{*}{ Wt.\% } & Min. & 0.52 & 0.50 & 0.17 & & & & & \\
\cline { 2 - 10 } & Max. & 0.60 & 0.80 & 0.37 & 0.035 & 0.035 & 0.25 & 0.25 & 0.25 \\
\hline
\end{tabular}

Table 2 Main mechanical behaviors of steel 55

\begin{tabular}{|c|c|c|c|}
\hline Density $(\mathrm{kg} / \mathrm{m} 3)$ & Young's strength $(\mathrm{GPa})$ & Harness $(\mathrm{HB})$ & Yield strength $(\mathrm{MPa})$ \\
\hline 7850 & 217 & 255 & 380 \\
\hline
\end{tabular}

The researched end mill cutters were solid carbide cutting tools. To improve the coolant effect and decrease heat load, different design can be adopted. Through altering the coolant channel geometry and the inletcutting fluid pressure, under conditions of the same pressure, in order to change the flow of the cutting fluid two different cooling channel geometries of double helical channels (DHC) and double straight channels (DSC) are investigated. Apart from the internally cooled channels, both of the selected end-mill cutters have the same exterior structure parameter.

\subsection{Experimental setup and End mill experiment}

The experiment was performed onvertical machining center (VMC1000P). And itfitted with fasted speed 15000 rpm. And Fig5 shows the experimental setup. The BT40 tool holder is adopted in thisinvestigation, and it can be matched with the central water outer machine spindle vertical machining center and the internally cooled endmilling tools. The cutting coolant is sprayed out to cutter rake surface of the end-milling tool and workpiece across the internally cooled channel. And DX-2 wireelectrode discharge machining cutting coolantmanufactured by Nanjing Special Oil Factory is adopted, and its ratio is 1:10. Table.3 showed the cutting coolant main property parameters. So as to study the function of internally cooled channel, the cutting fluid was supplied at a fixed pressure of $0.3 \mathrm{Mpa}$. Two experiment conditions were performed in the end mill experiment and details are illustrated in Table. 4. And to effectively reduce experiment error, the tests had been repeated 3 times.

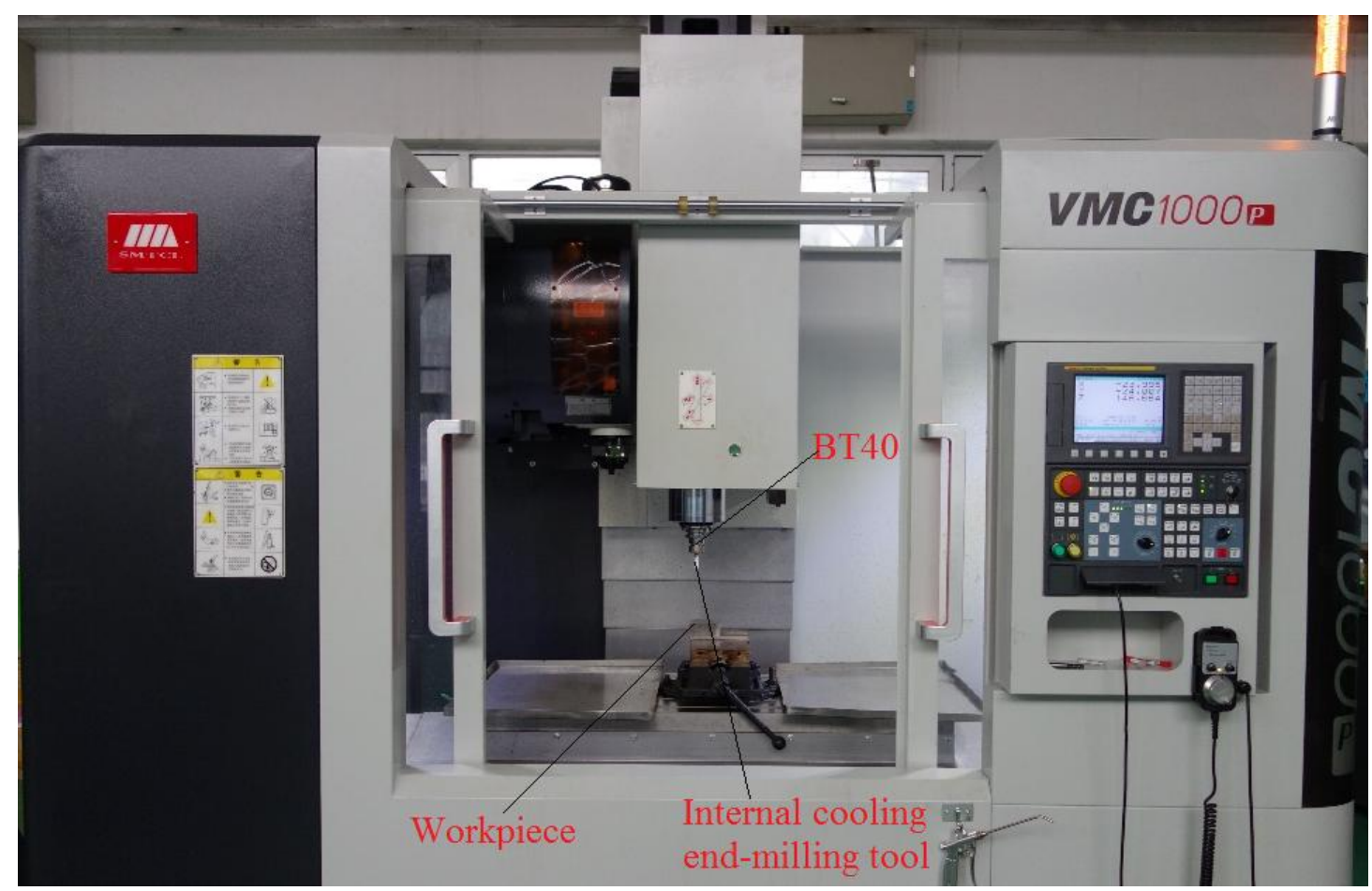

Fig 5: Experimental setup

ISSN: 0010-8189

(C) CONVERTER 2021

www.converter-magazine.info 
Table 3Properties of Cutting Fluid

\begin{tabular}{|c|c|c|c|c|}
\hline $\begin{array}{c}\text { Density } \\
\left(\mathrm{kg} \cdot \mathrm{m}^{-3}\right)\end{array}$ & $\begin{array}{c}\text { Kinematic } \\
\text { viscosity } \\
\left(\mathrm{mm}^{2} \cdot \mathrm{s}^{-1}\right)\end{array}$ & $\begin{array}{c}\text { Thermal } \\
\text { Conductivity } \\
\left(\mathrm{W} \cdot(\mathrm{m} \cdot \mathrm{K})^{-1}\right)\end{array}$ & $\begin{array}{c}\text { Dynamic } \\
\text { viscosity } \\
\left(\mathrm{kg} \cdot(\mathrm{m} \cdot \mathrm{s})^{-1}\right)\end{array}$ & $\begin{array}{c}\text { Specific heat } \\
\left(\mathrm{Wh} \cdot(\mathrm{kg} \cdot \mathrm{K})^{-1}\right)\end{array}$ \\
\hline 1010 & 0.90 & 0.6 & $9.023 \times 10^{-3}$ & 0.98 \\
\hline
\end{tabular}

Table 4Experiment conditions for end mill experiment

\begin{tabular}{|c|c|c|c|c|c|}
\hline & Speed $(\mathrm{m} / \mathrm{min})$ & $\begin{array}{c}\text { Hole diameter } \\
(\mathrm{mm})\end{array}$ & RPM & Feed $(\mathrm{mm} /$ tooth $)$ & $\begin{array}{c}\text { Coolant } \\
\text { channel }\end{array}$ \\
\hline Test 1 & 376.8 & 16 & 10000 & 0.12 & DHC \\
\hline Test 2 & 376.8 & 16 & 10000 & 0.12 & DSC \\
\hline
\end{tabular}

\section{Results and Discussion}

\subsection{Simulation results}

In high-speed milling process, the end milling tool performs high-speed rotary motion, and the cutting fluid is sprayed from the internally cooled channels to the bottom of the hole with a certain pressure.

In order to estimate the effect of internally cooled channel geometries, some models have been numerically simulated. Fig 6 shows the velocity field for the end mill with DSC and DHC internally cooled channel. Because of the curved internally cooled channel in DHC end-milling cutter, the speed of the cutting coolant at the outlet is reduced by the curved internally cooled channel, the cutting fluid velocity magnitude of the DHC end-milling tool is slightly smaller than that at the outlet of the DSC end-milling tool. After the cutting is sprayed out of the DSC end-milling tool, part of the cutting fluid is changed direction and flows down the rake surface of the end-milling tool, and another part flows to the machined surface of workpiece. While in the DHC end-milling tool, the outlet direction of the internally cooled holes forms a certain angle with the axis of the end-milling tool, so most of the cutting fluid mainly directly flows to the rake face of the corner. Furthermore, it is good to chip evacuate. At the same time, the cooling effect of DHC end-milling tool is superior to DSC end-milling tool. And the DHC internal channel especially improves the cooling of the outer corner.

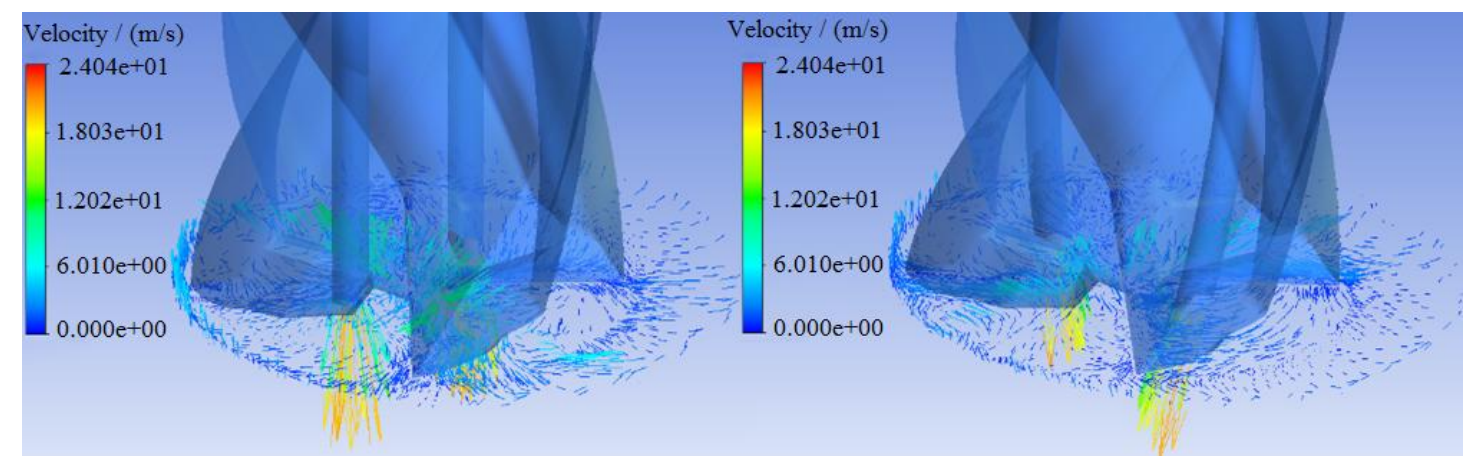

(a)DSCinternally cooled channel (b) DHC internally cooled channel

Fig 6: Velocity field for the end mill with DSC and DHC internally cooled channel

The pressure field of the DSC end-milling tool and the DHC end-milling tool is shown as Fig7. At the moment that cutting coolant sprays to the bottom of the hole, the cutting coolant pressure of the DSC end-milling tool is larger than that of the DHC end-milling cutter. But this angle of the outlet direction from that internally cooled holes with the axis of the end-milling cutter is to promote the flow of cutting fluid at the bottom of the hole, particularlyat the contact of the cutting edge and hole wall. So the minimum pressure zone in DHC end-milling tool is less than that in the DSC end-milling tool. And the effect of cooling and lubrication is increased in DHC end-milling tool.

ISSN: 0010-8189

C) CONVERTER 2021

www.converter-magazine.info 


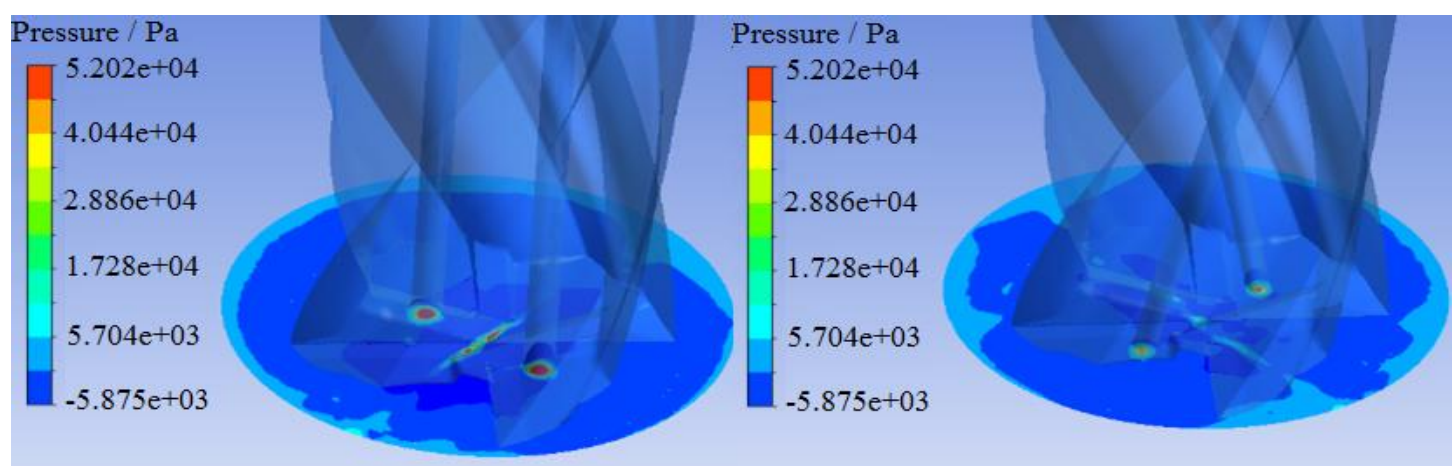

(a)DSC internally cooled channel (b) DHC internally cooled channel

Fig 7: Pressure field for the end mill with DSC and DHC internally cooled channel

At the same time, it can also be found that the dead zone close cutting edge in the DSC is much larger than whichin the DHC. Especially, the more dead surface areaclose the external corner generates slowly cutting fluid flow. The too slowly flowing is not beneficial to remove chip. The mixture of cutting fluid and accumulated chip affects the quality of the workpiece machined surface.

\subsection{Experiment results}

This experiment was conducted under a pressure of $0.3 \mathrm{MPa}$ for both internally cooled channel structures, and the machined surface of the bore was also researched. Thus the surface roughness and the cylindricity were analyzed.

The machined workpiece surface roughness with different internally cooled hole structures is shown as Fig 8 . The experimental values are presented asbroken line chart, and in the broken line chart the red line indicates the surface roughness of the machined bore surface with DHC internally cooled channel end-milling cutter. The surface roughness has been measured on three different positions of the same hole, and then the average surface roughness of every hole can be gotten. The values in the red line are all greater than that in the blue line. Therefore, the surface roughness value is small overall. To some extent, the quality of hole milled with DHC end-milling tool. This is mainly because that there is horizontal component in DHC end-milling tool, it not only benefits cutting fluid flowing at the bottom of the hole, and will continue to the removal of the chip.

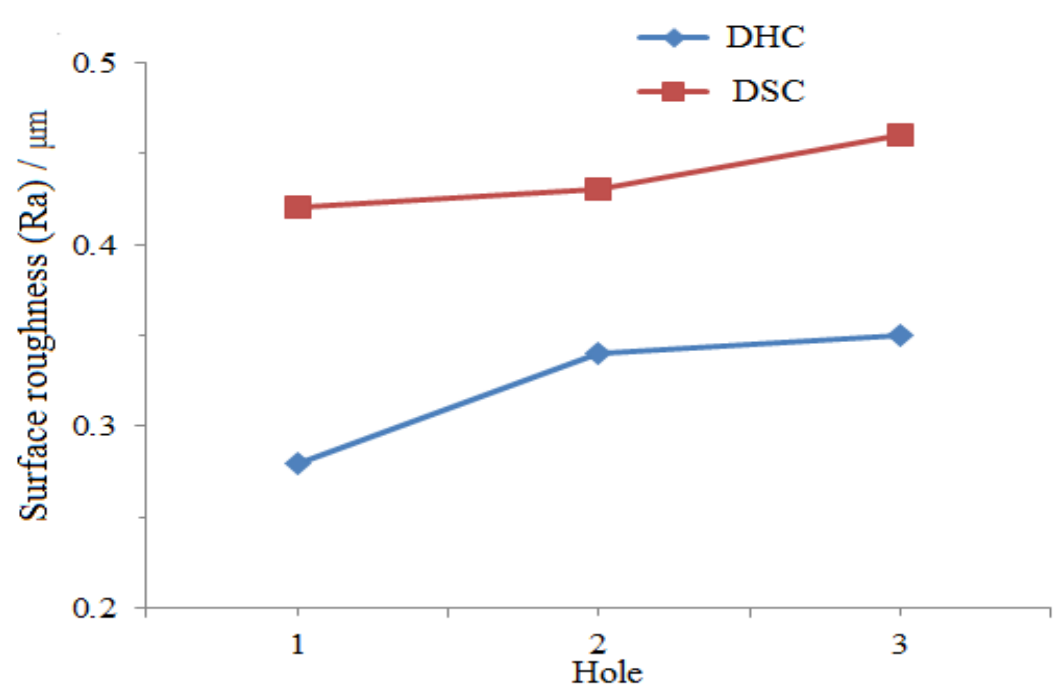

Fig 8: Surface roughness (Ra)

ISSN: 0010-8189

www.converter-magazine.info 
The cylindricity of the holes milled with different internally cooled channel structures mas measured on WENZE LH65 coordinate measuring machine is shown in Fig9. It is easy to see that both the cylindricity results with DSC and DHC end-milling tool are all lower than $0.02 \mathrm{~mm}$ and can both satisfy the generally mechanical precision requirement. On closer inspection, the cylindricity results milled with DHC are all less than $0.013 \mathrm{~mm}$, and are all smaller than that milled with DSC end-milling tool.

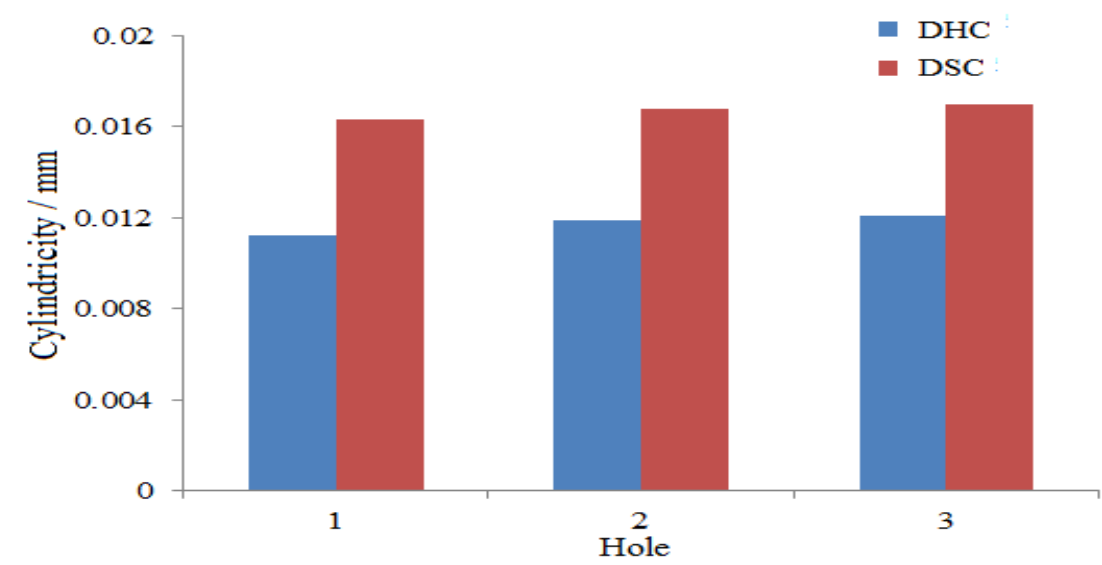

Fig 9: Cylindricity

\section{Conclusion}

The aim of thispaper is to analyze the influences with different internally cooled channels on the machinedworkpiece surface. Because of the smaller dead zone of the cutting fluid in DHC than in DSC endmilling tool and as much as possible cutting fluid closing to the rake surface, a greater heat transfer rate can be gotten in DHC end milling tool. The horizontal component in DHC end-milling tool is good to the cutting fluid flowing at the bottom of the hole and removal of the chip, so both of the surface roughness and cylindricity milled with DHC end-milling tool are lower than that milled with DSC end-milling tool. Thus the machined surface quality of the workpiece with DHC end-milling tool is high, which implies that DHC end-milling tool should be recommended.

\section{Acknowledgements}

This research was supported by the scientific research start-up funds of Guangdong Ocean University (E15168)

\section{References}

[1] Z. Wu, Y. Yang, C. Su, et al., "Development and prospect of cooling technology for dry cutting tools,"The International Journal of Advanced Manufacturing Technology, vol. 88, no. 5-8, pp. 1567$1577,2017$.

[2] J. Ma, X. Ge, C. Qiu, et al., "FEM assessment of performance of microhole textured cutting tool in dry machining of Ti-6Al-4V," The International Journal of Advanced Manufacturing Technology, vol. 84, no. 9-12, pp. 2609-2621, 2016.

[3] Y. Shen, Y. Liu, W. Sun,et al., "High-speed dry compound machining of Ti6Al4V," Journal of Materials Processing Technology, vol. 224, pp. 200-207, 2015.

[4] Y.Q. Xing, J.X. Deng, K.D. Zhang, et al., "Fabrication and dry cutting performance of Si3N4/TiC ceramic tools reinforced with the PVDWS2/Zr soft-coatings," Ceramics International, vol. 41, pp. 10261-10271, 2015.

[5] N.X. Yin, G.H. Li, G.Y. Tan, et al., "Experimental Research on Instantaneous Temperature Measurement of AISI 304 Stainless Steel in High-speed Milling Holes," Mechanical Science and 
Technology for Aerospace Engineering, vol. 38, No. 11, pp. 1766-1770, 2019 (In Chinese).

[6] C.L. Zhang, S. Zhang, X.F. Yan, et al., "Effects of internally cooled channel structures on cutting forces and tool life in side milling of H13 steel under cryogenic minimum quantity lubrication condition," The International Journal of Advanced Manufacturing Technology, vol. 83, no. 5-8, pp. 975-984, 2016.

[7] H. Zhao, G.C. Barber, Q. Zou, "Effects of internally cooled channel structures on cutting forces and tool life in side milling of H13 steel under cryogenic minimum quantity lubrication condition," The International Journal of Advanced Manufacturing Technology, vol. 83, no. 5-8, pp. 975-984, 2016.

[8] Z. Wang, K. Rajurkar, “Cryogenic machining of hard-to-cut materials," Wear, vol. 239, no. 2, pp. 168$175,2000$.

[9] Z.R. Qiang, M.P. Wu, X.J. Miao, et al., "CFD research on particle movement and nozzle wear in the abrasivewater jet cutting head," The International Journal of Advanced Manufacturing Technology, vol. 95, no. 9-12, pp. 4091-4100, 2018.

[10] F. Fallenstein, J.C. Aurich, "CFD based investigation on internally cooled of twist drills," Prodedia CIPP, vol. 14, pp. 293-298, 2014. 